\title{
Influence of Milling Time During the Mechanical Alloying Process on the Properties of Fe-3Si-0.75P Alloy
}

\author{
Leandro Pelegrini ${ }^{a *}$, Sérgio Deitos Bittencourta, Philippe Paulettia \\ José Carlos Krause de Verney ${ }^{b}$, Moisés de Mattos Dias', Lírio Schaeffer ${ }^{d}$
}

\begin{abstract}
${ }^{a}$ Grupo de Desenvolvimento em Energias Renováveis - GDER, Centro de Tecnologia, Universidade Federal do Rio Grande do Sul - UFRGS, Av. Bento Gonçalves, 9500, CEP 91501-970, Porto Alegre, RS, Brazil

${ }^{b}$ Pós-graduação em Materiais e Processos Sustentáveis, Universidade Luterana do Brasil - ULBRA, Av. Farroupilha, 8001, CEP 92425-900, Canoas, RS, Brazil

${ }^{c}$ Mestrado Profissional em Tecnologia de Materiais e Processos Industriais, Instituto de Ciências Exatas e Tecnológicas - ICET, Universidade FEEVALE, Novo Hamburgo, RS, Brazil

${ }^{d}$ Laboratório de Transformação Mecânica - LdTM, Centro de Tecnologia, Universidade Federal do Rio

Grande do Sul-UFRGS, Av. Bento Gonçalves, 9500, CP 15021, CEP 91501-970, Porto Alegre, RS, Brazil
\end{abstract}

Received: July 29, 2015; Revised: August 19, 2015

In this study the soft magnetic alloy Fe-3Si-0.75P (wt\%) was obtained by mechanical alloying through powder metallurgy. The processing included the formulation of metallic powder, wet milling for $1 \mathrm{~h}, 3 \mathrm{~h}, 6 \mathrm{~h}$ and $9 \mathrm{~h}$, in an attritor mill using alcohol P.A. as a lubricant. Cold compaction was then performed in a floating die under $600 \mathrm{MPa}$ pressure and, finally the ring-shaped test specimens were sintered at $1150{ }^{\circ} \mathrm{C}$ for $1 \mathrm{~h}$. The electrical, physical and magnetic properties were then analyzed using the following assays: Laser granulometry, density, metallography, hysteresis curve and $\mathrm{AC}$ permeability, resistivity and XRD. The results showed a strong influence of milling time on magnetic properties of the alloy. There was a decrease in grain size with the milling time, which is likely the cause of increased in magnetic properties.

Keywords: powder metallurgy, mechanical alloying, soft magnetic materials

\section{Introduction}

A soft magnetic material may be used as an efficient flow multiplier in a great variety of devices, presenting challenges for the understanding of their properties, preparation and characterization ${ }^{1}$. Soft magnetic materials come in various forms, ranging from pure iron used in inductor cores, sheets of rolled silicon steel sheets, nanocrystalline or amorphous bands for transformers, and ferrites for electromagnetic interference filters $(\mathrm{EMI})^{2}$. The characteristics of these materials are their high permeability, low remanence and coerciveness, high induction of saturation, low energy loss by hysteresis and low loss by Foucault currents in alternated flux applications ${ }^{3}$. The selection of materials for each application is important, providing the best balance between performance and $\operatorname{cost}^{2}$.

It is important to know the requirements of the materials in order to produce the best soft magnetic components. High magnetization of saturation and remanence require powders with good compaction properties. Low coercive force and high permeability require clean materials that are a characteristic of powder metallurgy ${ }^{4}$. Intensive development of materials obtained from powders has been replacing the traditional electrical steels more frequently $y^{5}$. Pure iron pieces obtained by powder metallurgy have a very low resistivity and, therefore, suffer great magnetic losses due to the high amount of Foucault current generated. Si is added to

*e-mail: le_pelegrini@yahoo.com.br increase its resistivity. Besides, the addition of $\mathrm{P}$ activates the sintering process in $\mathrm{Fe}-\mathrm{Si}-\mathrm{P}$ alloys ${ }^{6}$.

A functional powder processing technique that can produce a variety of alloys with phases in balance or non-balance is mechanosynthesis. The advantage of this technology is that the powder can be produced in large quantities and the processing parameters can easily be controlled. Hence, it is an appropriate method for commercial applications. The mechanical synthesis of Fe-based magnetic alloys leads to forming a multiphase, supersaturated solid solution or possibly an amorphous structure ${ }^{7}$. Numerous studies and patents report on the mechanical synthesis of materials with better mechanical, magnetic or catalytic properties ${ }^{8}$. At the initial stage of the process, the particles are deformed, over each other, so as to form a layered structure, where they are again refined during milling. Due to a great plastic deformation, the resulting powder mixture reduces the interdiffusion distance of the constituent elements on the order of micrometers .

\section{Experimental Procedures}

\subsection{Processing}

The Fe-3Si-0.75P alloy was chosen for the magnetic properties of Si and P. The formulation of the Hoganas ${ }^{\circledR}$ metallic powders consisted of pure Fe (D90 between 45 and $150 \mu \mathrm{m}$ ), 
Si corresponding to a composition of $45 \%$ wt. in Fe and $\mathrm{P}$ due to the iron-based alloy with an $\mathrm{Fe}_{3} \mathrm{P}(16 \%$ wt. of $\mathrm{P})$ composition. Thus, only milling time was varied.

Milling was done as a speed of $600 \mathrm{rpm}$ for $1 \mathrm{~h}, 3 \mathrm{~h}, 6 \mathrm{~h}$ and $9 \mathrm{~h}$ in an attritor mill. P.A. alcohol was used as a lubricant (1:1 - powder/lubricant). Five kilograms of stainless steel spheres were added $(\Phi=6 \mathrm{~mm})$ and $140 \mathrm{~g}$ of powder, which correspond to approximately $30 \%$ of the mill capacity at a ratio of 1:25 (powder/spheres). The mill has a volume around $5.1 \mathrm{~L}$.

After milling, the material was dried at $50-70{ }^{\circ} \mathrm{C}$ until the weight was completely stabilized. Later, zinc stearate $(2 \% w t)$ was added to the milled powder and it was mixed for about 20 min to homogenize the powder with the lubricant used. Powder compaction was performed cold in a hydraulic press under $600 \mathrm{MPa}$ pressure to produce ring-shaped test specimens (Rowland ring).

Next the pieces were sintered at $1150^{\circ} \mathrm{C}$ for 60 minutes in step, in a tubular oven under an argon gas atmosphere. It was kept for 30 minutes in step at $550{ }^{\circ} \mathrm{C}$ to eliminate/calcine lubricant. Thus, the thermal cycle followed, with cooling in the oven itself.

\subsection{Measurements of magnetic properties}

After sintering, the hysteresis test was carried out based on standard ASTM A773/A773M-0 $1^{10}$. The piece/coil and the secondary/primary coil contact were insulated with polypropylene. After sintering the piece has a $5 \mathrm{~cm}$ in diameter (Rowland ring). It was coiled and, finally, a Hysteresis Curve Tracer (TLMP-TCH) was used.

In this test, besides the hysteretic properties, it was possible to obtain the magnetization curve, saturation induction and maximum permeability $\left(\mu_{\mathrm{m}}\right)$. Electrical resistivity was determined from the electrical resistance using a milivoltimeter. On the other hand, the grain size distribution was performed in a Laser Granulometer using Cilas (model 1180L) equipment. The X-Ray Diffraction test was performed with a Phillips X'Pert MPD diffractometer with a $\mathrm{Cu}$ anode and $40 \mathrm{kV}$ and $40 \mathrm{~mA}$ radiation. The density of the pieces was measured using two different methods: the Geometrical Model for the green pieces and the Method by Archimedes for sintered pieces.

In addition, the morphology of milled powder was analyzed using the Scanning Electron Microscope, model JEOL JSM 6060, using an acceleration voltage of $20 \mathrm{kV}$ and $1000 \mathrm{X}$ augmentation. The OLYMPUS Optical Microscope was used to analyze the morphology, grains, grain size and phases present in the sintered samples.

\section{Results and Discussion}

First the apparent density of powders was performed and the results are shown in Figure 1. Using the graph of $d_{A P}$, a drop in the apparent density of the powder is noted, with increased milling time. Without milling it was $4.5 \mathrm{~g} / \mathrm{cm}^{3}$, by one hour it was already around $1 \mathrm{~g} / \mathrm{cm}^{3}$. After the increasing of the milling there is a slight increase in the apparent density of the powder.

This reduction was, in a way, expected, because of the internal deformation of the particles caused by mechanosynthesis performed with high energy. Besides, this low density is also related to the irregular shape of the powder after milling (flake type), which will be discussed later, and impairs processing, especially in the compaction of test-specimens, and must be controlled with appropriate techniques. In other words, the apparent density of the powder being low after mechanosynthesis, the powder becomes "bulkier", with internal voids, generating a low densification of the green piece after compaction.

The laser granulometry test of the powder can see in Figures 2 and 3 (CILAS 1064 equipment - error: 0.5\%). It is noted that in both: mean particle size, D50 and D90, is reduced with the milling time, and tends to remain constant after $3 \mathrm{~h}$ of milling (Figure 2). Figure 3 shows that the particle size distribution curve is displaced to the left, with a tendency to increase its range (size distribution).

Based on the SEM images (Figure 4), it is noted that, as the particle size decreases, because of the increased milling time, the particle morphology also changes. Initially there

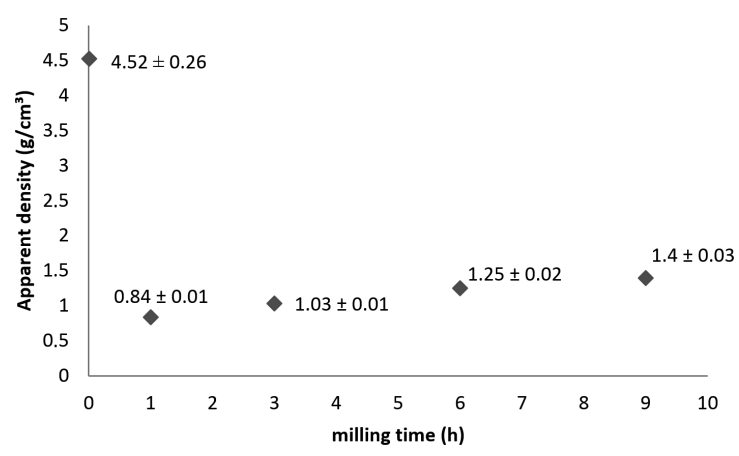

Figure 1. Powder apparent density x milling time.

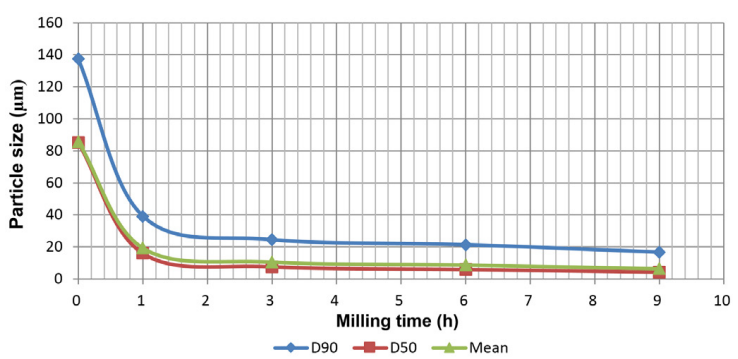

Figure 2. Particle diameter of powders at different milling times.

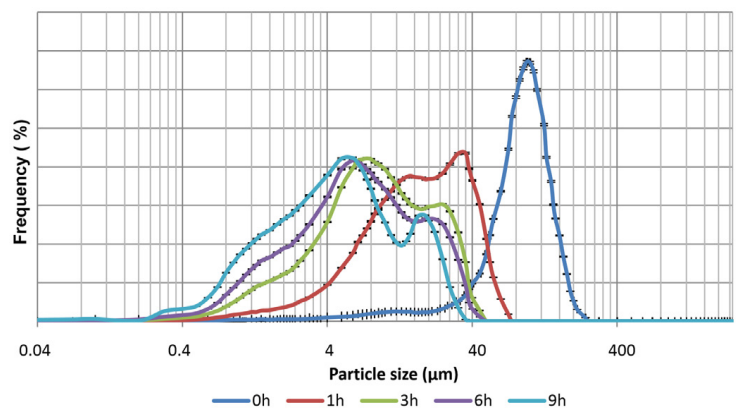

Figure 3. Histogram; frequency x milling times. 


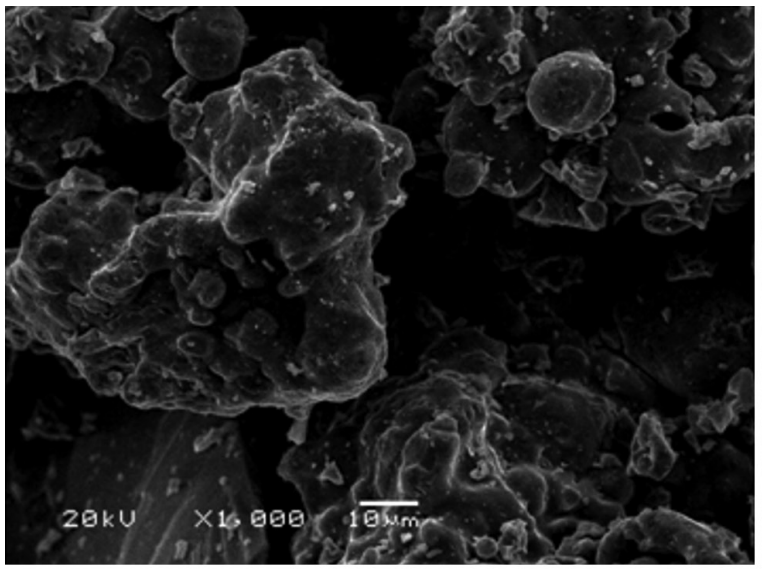

(a)

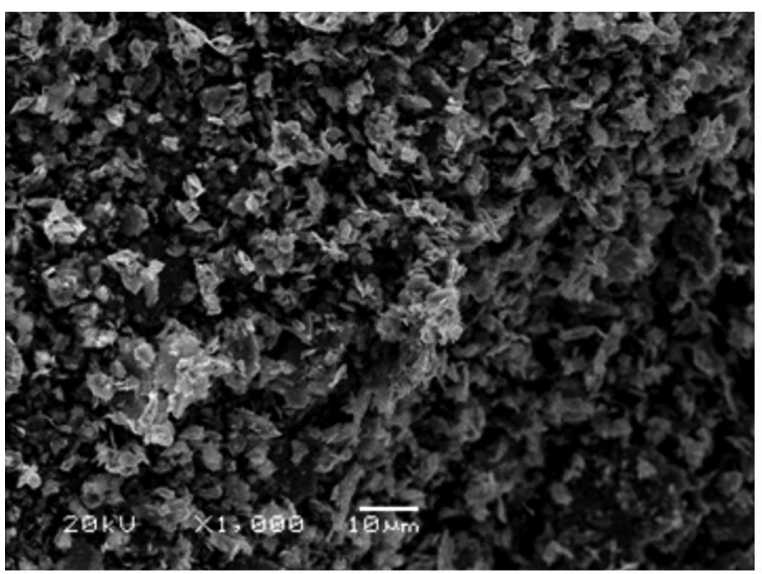

(c)

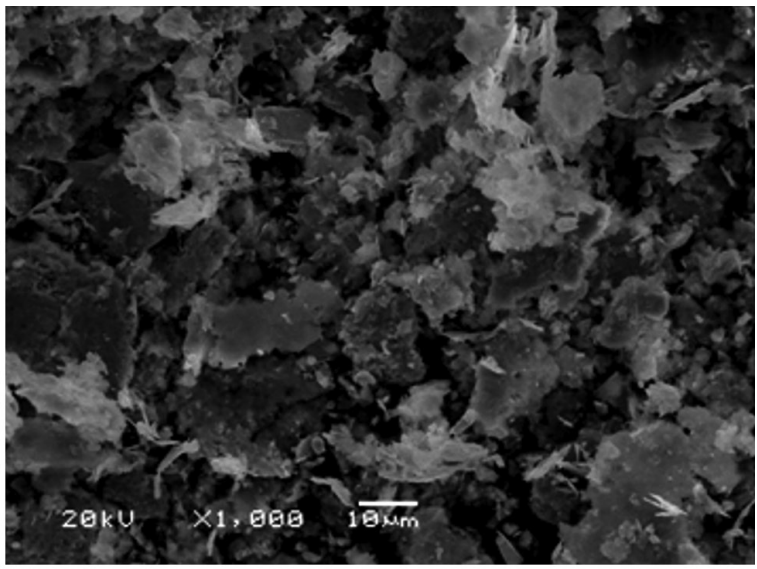

(b)

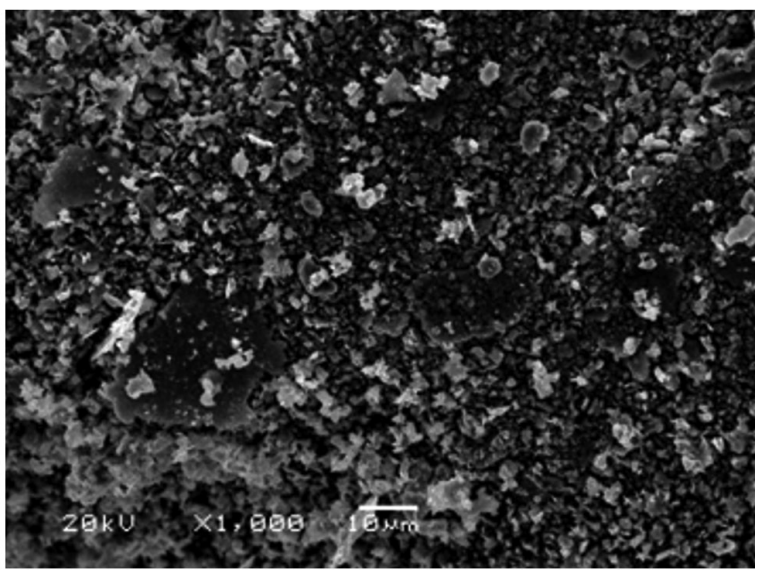

(d)

Figure 4. Milled powder micrographs (SEM) - (a) 0 h, (b) 1 h, (c) $3 \mathrm{~h}$ and (d) $9 \mathrm{~h}$.

is a spherical shape of the mixed powder $(0 \mathrm{~h})$, due to the processing of atomization, in $1 \mathrm{~h}$, the powder is found in a flattened shape. On the other hand, after $3 \mathrm{~h}$ it has an irregular shape, maintaining the same shape at $9 \mathrm{~h}$ of milling ${ }^{11}$.

Figure 5 presents green and sintered density of the ring-shaped test specimens, respectively. A reduction of density is seen with increased time of milling. This is related to the apparent density of the powder and its compressibility.

On the other hand, the retraction of the piece diameter shows a significant increase, with increased milling time. This is explained as due to the apparent density of powder and, consequently, of the green pieces after compaction, discussed previously. There is more free space between the particles of the samples after compaction. Thus, when sintered, the pieces, due to the filling of empty spaces left by the pores, strongly retract by consolidating and densifying the pieces and reduction of the pores caused by the sintering process itself. The shape of the particles also corroborates this result.

It is noticed that after only 1 hour of milling retraction was around $10 \%$ and $14 \%$ of the outer and inner diameter, respectively. There was also a significant increase for pieces with up to $9 \mathrm{~h}$ of milling. This causes or may cause problems of dimensional precision, warping of the pieces, besides

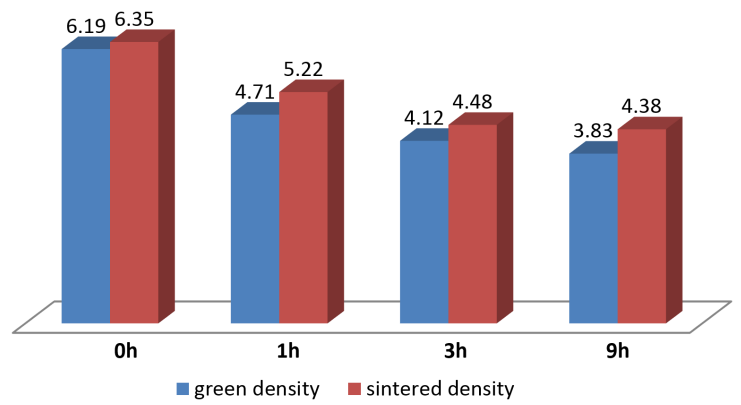

Figure 5. Green and sintered density of specimens.

the need for an appropriate design of the dies to take these changes into account. The retraction of the sintered piece ( $1 \mathrm{~h}$ milling) was greater than that of the piece where only mixed powder was used $(0 \mathrm{~h})$.

The curves obtained by XRD can be seen in Figure 6 . The graph shows the characteristic peaks of the phases, Fe alpha $(2 \theta=44.8 ; 65.15)$. The increased milling time is accompanied by a broadened line and a marked reduction 


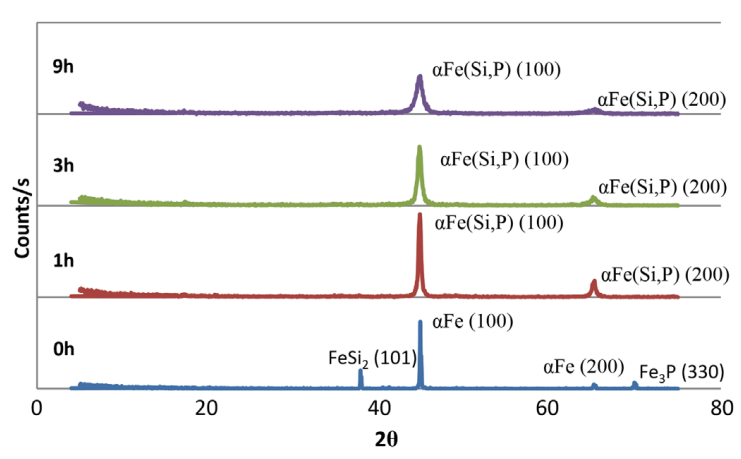

Figure 6. XRD with $0 \mathrm{~h}, 1 \mathrm{~h}, 3 \mathrm{~h}$ and $9 \mathrm{~h}$ of milling ${ }^{12}$.

of intensity caused both by became amorphous and by the increased internal deformation during milling. The peaks of the $0 \mathrm{~h}$ material, close to $38^{\circ}$ and $70^{\circ}$ are the phases of the $\mathrm{FeSi}_{2}$ and $\mathrm{Fe}_{3} \mathrm{P}$ alloys, respectively, present in the material. They disappeared after milling, showing that they entered solid solution in Fe alpha. Admitted the peak itself $\alpha \mathrm{Fe}$ ( $\mathrm{Si}, \mathrm{P}$ ) (100) based on crystallography by the patterns obtained in the data base, although it was not performed the "Rietveld refinement" to be sure that there is no iron peak overlapped with $\alpha \mathrm{Fe}(\mathrm{Si}, \mathrm{P})(100)$ one.

Looking at the XRD graph, phase $\mathrm{FeSi}_{2}(2 \theta=37.8)$ was found in the data base of the characteristic peaks of the materials ${ }^{12}$. This iron-based alloy supplied by the manufacturer contains around $50 \%$ to $67 \% \mathrm{Si}$, i.e., since the specifications say that it has $40 \% \mathrm{Si}$, it was concluded that pure iron was added to it until it reached the desired stoichiometry. Phase $\mathrm{Fe}_{3} \mathrm{P}$ is from the $\mathrm{Fe} 16 \% \mathrm{P}$ alloy, used in the test, seen in the graph $(2 \theta=69.34)$ according to Lisher et al. ${ }^{13}$.

According to Kumar et al., the reduction of peak intensity is directly related probably due to the crystallite size $^{14}$. For material that has only been lightly mixed, evidently there is greater crystallinity because the peaks are narrower. As milling time increases, the material becomes less crystalline and the peaks become wider. These characteristics significantly affect the magnetic properties of the material ${ }^{15}$.

As to the phases of the Fe-Si-P alloy, using 3\% silicon, the sintered material presents in the $\mathrm{BCC}$ according to the $\mathrm{Fe}-\mathrm{Si}$ diagram, i.e., alpha iron in the BCC form, with silicon in solid form in the iron. On the hand, for the phosphorus used in $\mathrm{Fe}_{3} \mathrm{P}$ form, there is $16 \%$ of $\mathrm{P}$ in the iron. Thus, the $\mathrm{Fe}-3 \mathrm{Si}-0.75 \mathrm{P}$ has $\mathrm{Si}$ and $\mathrm{P}$ in solid solution in iron after milling. Additions of $\mathrm{Si}$ and $\mathrm{P}$ produce magnetic alloys that present a permeability higher than 5000 . Besides the benefits of magnetic performance, Si supplies ferrite and has shown a positive effect on the resistance and ductility of material obtained by $\mathrm{P} / \mathrm{M}^{16}$.

Since this $\mathrm{Fe}-\mathrm{Si}$ system does not present a liquid phase at $1150{ }^{\circ} \mathrm{C}$, Si does not disseminate homogeneously in pure Fe during sintering. This leads to inferior magnetic properties than those of Fe-P. The addition of $\mathrm{P}$ in the $\mathrm{Fe}_{3} \mathrm{P}$ form allows obtaining the desired mechanical properties using lower sintering temperatures, due to the formation of a transient liquid phase. Besides, P stabilizes ferrite, leading to greater density after sintering. Its addition also promotes increased hardness due to the presence of phosphorus as a solid solution and the presence of phase $\mathrm{Fe}_{3} \mathrm{P}^{17}$.

Figure 7 shows the micrographs obtained by O.M. of the pieces of $0 \mathrm{~h}, 1 \mathrm{~h}, 6 \mathrm{~h}$ and $9 \mathrm{~h}$, respectively. It is noted that the porosity of the piece obtained with $0 \mathrm{~h}$ powder is more localized at certain points with larger dispersed pores. For $1 \mathrm{~h}$ there are irregular-shaped pores, slightly better distributed throughout the piece. The $6 \mathrm{~h}$ one has a microstructure with pores tending to a spherical shape. Finally the $9 \mathrm{~h}$ one presents more spherical, better distributed pores. It is possible to see that there is a difference among the grain size after sintering. From Figure $7 \mathrm{a}$ the grain size is about $50 \mu \mathrm{m}$ and by the Figure $7 \mathrm{~d}$, the grain size diminishes more than $50 \%$, about $20 \mu \mathrm{m}$.

After this, the magnetic hysteresis tests were performed, with a frequency of $0.05 \mathrm{~Hz}$, and the AC permeability test, with a frequency of $0.1 \mathrm{~Hz}$; both with $1 \mathrm{~A}$ current. The magnetic hysteresis curve (Figure 8) found in the hysteresis test performed is a curve characteristics of soft magnetic materials, with a narrow band of the hysteresis cycle (easy magnetization).

Looking at the results obtained in the hysteresis test, it is noted that after 1 hour of milling, there was a greater induction of saturation than for the material that is only mixed $(0 \mathrm{~h})$, and after 3 hours of milling there was increased induction and a reduction from this time on. Further, coercivity had a slight increase after 1 hour, remaining constant over time.

The initial increase of coercivity originates in residual stress, impurities, pores and defects, which are induced during milling. Severe plastic deformation of powders increases the imperfections of the reticulate and, consequently, increases its deformation ${ }^{18}$.

These variations of micro-deformities and size of the crystals after hours of milling may be ascribed to the increased temperature on the surface of the powders during a long milling time. Coercivity increases as the grain size diminishes, increasing considerably with the introduction of internal deformation in the material, which is inevitably related to the process. The impurities or non-magnetic inclusions increase coercivity by confining the walls of the magnetic domain. To reduce coercivity, the value of all these parameters must be low. Coercivity depends on the grain size and induction of saturation ${ }^{16}$.

As to the result obtained through the magnetization test (Figure 9), it is noticed that an increased saturation induction occurs for the samples obtained using the milled powder and, in $3 \mathrm{~h}$, there is the peak of the highest saturation induction with a decrease from then on. The maximum permeability for the material milled during $1 \mathrm{~h}$ was the best of all (2840), against 1350 for $0 \mathrm{~h}$, which is shown in Table 1 .

Saturation induction increases with milling time, excepting with $9 \mathrm{~h}$. This may be ascribed to the increased network parameter with long milling times, and the reduction of magneto-crystalline anisotropy due to grain refinement. With small grain sizes, each grain can be treated as a simple magnetic domain, eliminating the influence of the magnetic walls ${ }^{19}$. It is noted that the highest value of these two properties is obtained between $1 \mathrm{~h}$ and $3 \mathrm{~h}$ of milling. Saturation induction increases with milling time up to $3 \mathrm{~h}$ and from then on diminishes until $9 \mathrm{~h}$ of milling. The coercivity increases with decreasing grain size after $1 \mathrm{~h}$, although the 


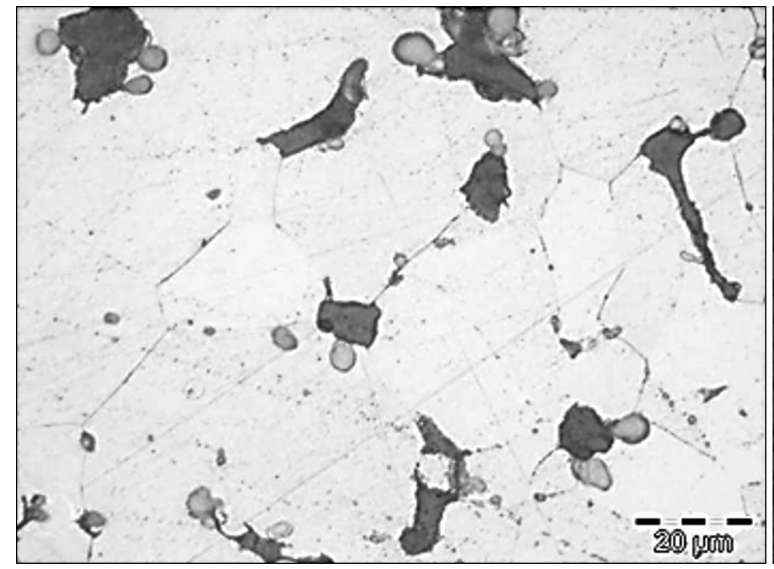

(a)

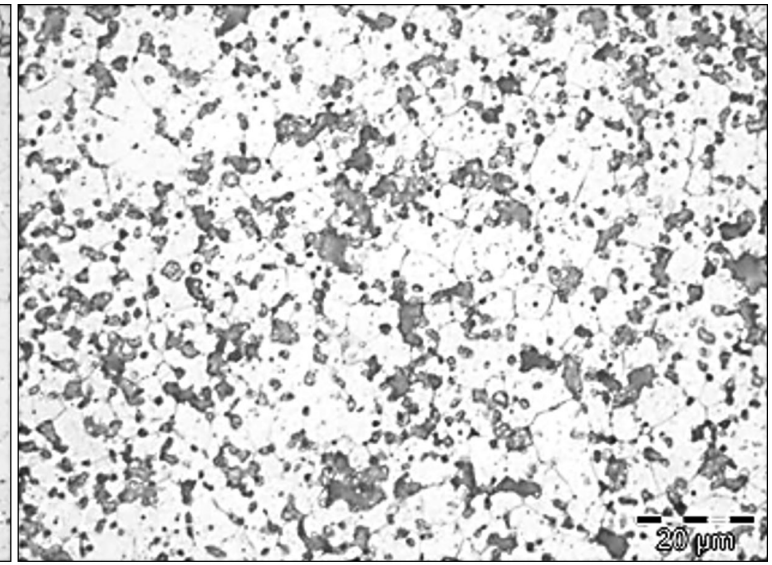

(b)

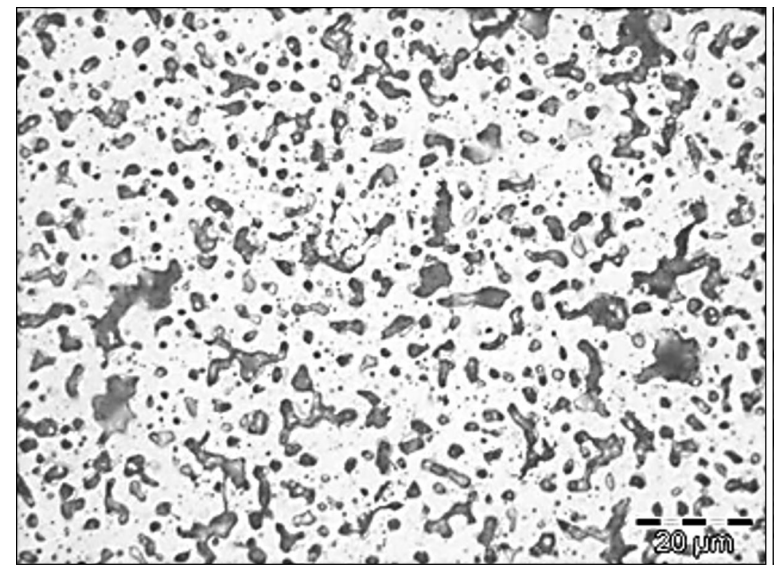

(c)

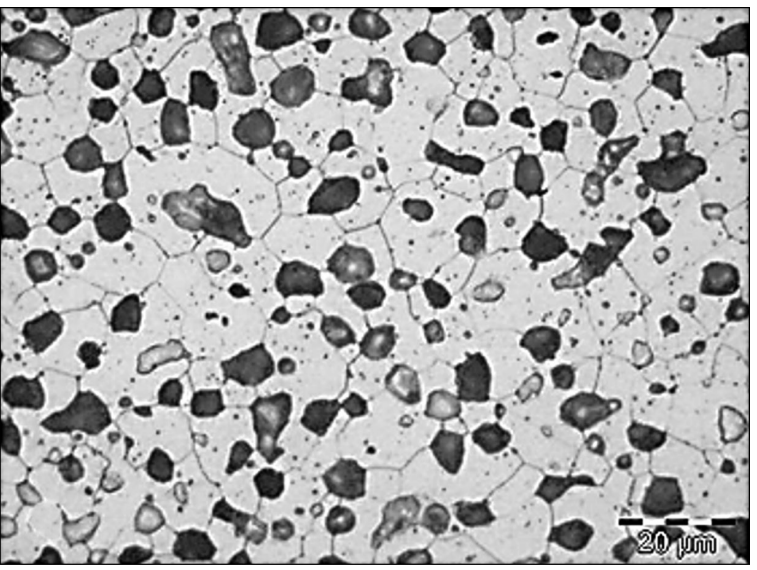

(d)

Figure 7. Micrograph of alloy: FeSiP - (a) 0h, (b) 1h, (c) $6 \mathrm{~h}$ and (d) 9 h. Attack with Nital 2\%.

Table 1. Magnetic and electrical properties of the alloy Fe-3Si-0.75P after milling.

\begin{tabular}{|c|c|c|c|c|c|c|}
\hline \multirow{2}{*}{$\begin{array}{c}\text { Milling } \\
\text { Time } \\
{[\text { [h] }}\end{array}$} & $\begin{array}{l}\text { Resistivity } \\
(\rho)\end{array}$ & $\begin{array}{c}\text { Saturation } \\
\text { Induction (Bs) }\end{array}$ & Remanence $\left(B_{r}\right)$ & Coercivity $\left(\mathrm{H}_{\mathrm{c}}\right)$ & Hist. Losses. & \multirow{2}{*}{$\begin{array}{c}\text { Max. } \\
\text { Perm. (calc.) } \\
\left(\mu c_{\text {máx }}\right)\end{array}$} \\
\hline & {$[\mu \Omega . \mathrm{m}]$} & [T] & [T] & {$[\mathbf{A} / \mathbf{m}]$} & {$[\mathrm{W} / \mathrm{kg}]$} & \\
\hline 0 & 0.45 & 0.98 & 0.55 & 166 & $5.49 \mathrm{E}-03$ & 1350 \\
\hline 1 & 1.07 & 1.05 & 0.82 & 432 & $1.43 \mathrm{E}-02$ & 2840 \\
\hline 3 & 0.42 & 1.15 & 0.80 & 509 & $1.66 \mathrm{E}-02$ & 1240 \\
\hline 9 & 0.25 & 0.88 & 0.61 & 439 & $1.31 \mathrm{E}-02$ & 1380 \\
\hline
\end{tabular}

Note: In bold are highlighted the best results achieved regarding magnetic properties of respective materials, obtained by powders of different milling times.

grain size, in Figure 7, hardly not varied between 3 and 9h, as seen before due to the powder agglomeration and the porosity increasing after the sintering process.

Table 1 shows the results for electrical and magnetic properties. The better ones are highlight on this table. The saturation and remanent induction was greater for the alloy with $3 \mathrm{~h}$ and $1 \mathrm{~h}$ of milling, respectively. Resistivity reached its highest value with $1 \mathrm{~h}$ of milling and diminished as the milling time rose. On the other hand the losses remained practically constant after milling for $1 \mathrm{~h}, 3 \mathrm{~h}$, and $9 \mathrm{~h}$, becoming greater than the alloy without milling $\left(5.49 \times 10^{-3} \mathrm{~W} / \mathrm{kg}\right)$. This is due to greater coercivity for the alloys which were ground, remaining in the $430-510 \mathrm{~A} / \mathrm{m}$ range as against 166 for the only mixed one. The best result for maximum relative permeability was achieved for the alloy without milling (1350), while the best result for maximum permeability was achieved for alloy with $1 \mathrm{~h}$ milling (2840). Increasing the milling time, we have an increase in losses for a core, a result that was already found by Shokrollahi \& Janghorban ${ }^{20}$.

These microstrain and crystal size variation after milling times can be attributed to the increased surface temperatures for a long time milling. The coercivity increases with decreasing grain size, increased considerably by introducing 


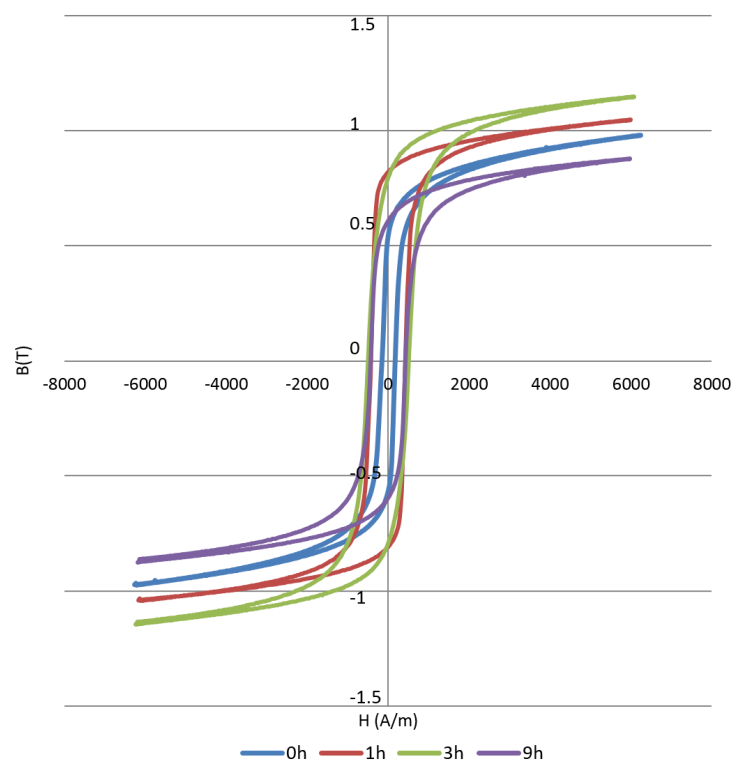

Figure 8. Hysteresis curve B x H of ferrous alloy, with different milling times.

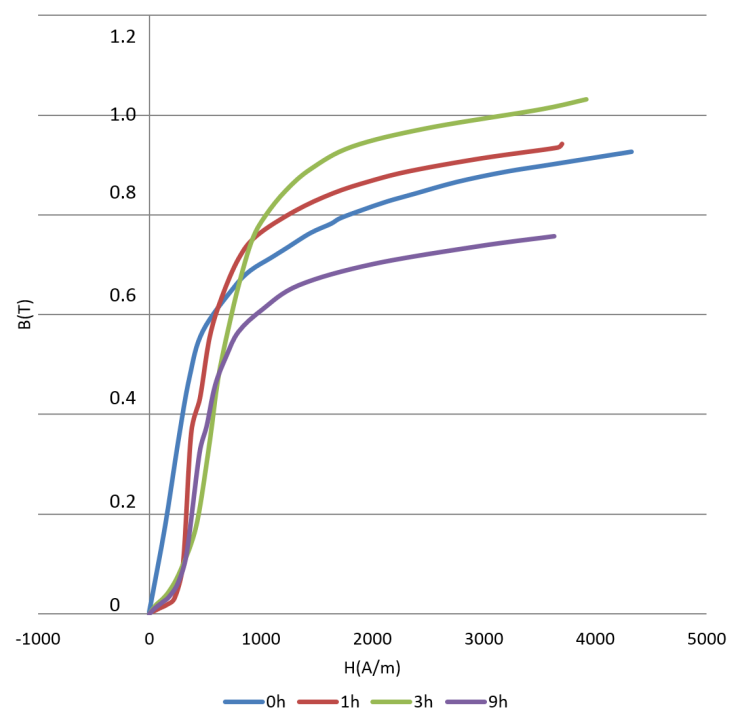

Figure 9. Magnetization curve (AC Permeability) of the ferrous alloy with different milling times.

\section{References}

1. Fiorillo F. Measurement and characterization of magnetic materials. 1st ed. Salt Lake City: Academic Press; 2004. 647 p.

2. Gutfleisch O, Willard MA, Brück E, Chen CH, Sankar SG and Liu JP. Magnetic materials and devices for the 21st century: stronger, lighter, and more energy efficient. Advanced Materials. 2011; 23(7):821-842. http://dx.doi.org/10.1002/adma.201002180. PMid:21294168.

3. Jiles DC. Recent advances and future directions in magnetic. Acta Materialia. 2003; 51(19):5907-5939. http://dx.doi. org/10.1016/j.actamat.2003.08.011. internal strain in the material, which is inevitably related to the process. The coercivity is an important identification factor of the soft magnetic behavior. The impurities or the nonmagnetic inclusions increased the coercivity through the pinning of the magnetic domain walls. To reduce the coercivity, the amount of all these parameters must be low. The coercivity depends on the crystal size (D), who normally influences the grain size, and the saturation induction $(\mathrm{Ms})^{18}$.

\section{Conclusion}

Characterizing the soft magnetic alloy chosen, Fe-3Si-0.75P, it was possible to demonstrate and analyze the influence on the magnetic properties of the material using the mechanosynthesis process. The alloy formation from $1 \mathrm{~h}$ of milling with $\mathrm{P}$ and $\mathrm{S}$ in a solid solution in the ferrite matrix was also demonstrated. This is interesting in the process, since it provides greater homogeneity of the material microstructure because of the diffusion of the alloy elements even before the sintering process.

Despite the increased coercivity and, consequently, the losses through hysteresis observed in the alloys after the milling process, there is a real increase in the induction of saturation of the material that underwent the mechanical alloying process. It was detected that, saturation induction increases with milling time up to $3 \mathrm{~h}$ and from then on diminishes until $9 \mathrm{~h}$ of milling due to the powder agglomeration generated by the $9 \mathrm{~h}$ of milling time and increasing of porosity after sintering ( $9 \mathrm{~h}$ sample) seen in the micrograph presented.

Finally, the processing of these materials should be optimized aiming at a greater densification of the alloy and also a reduction of retraction by increasing the compressibility of the material, as well as its apparent density. Further evaluation of the thermal treatment in the material may be useful to remove the internal deformation of the particles. New alloys, as well as new manufacturing techniques, are being studied, which will lead to the development of new alloys for the desired application.

\section{Acknowledgements}

The authors thank CAPES, CNPq and FAPERGS for the scholarships and project funding. LACER, through Prof. Dr. Carlos Bergmann, for the XRD and laser granulometry analyses. Also, Hoganas ${ }^{\circledR}$ for the support, offering metallic powders to perform this study.

4. Thorsen KA and Persson M. (2004). Soft magnetic materials - an introduction. International Sinter News. 4-5. Available from: <http://issuu.com/sinternews/docs/sinternews3en-gb.> Access in: 13/03/2015

5. Krawczyk A, Wiak S and Dolezel I. Advanced computer techniques in applied electromagnetics. 1st ed. Amsterdam: IOS Press; 2008. v. 30. 472 p.

6. Sharma D, Chandra K and Misra PS. Design and development of powder processed Fe-P based alloys. Materials \& Design. 2011; 32(6):3198-3204. http://dx.doi.org/10.1016/j.matdes.2011.02.046.

7. Shokrollahi H. The magnetic and structural properties of the most important alloys of iron produced by mechanical alloying. Materials \& Design. 2009; 30(9):374-387. 
8. Chicinas I, Pop V and Isnard O. Synthesis of the supermalloy powders by mechanical alloying. Journal of Materials Science. 2004; 39(16-17):5305-5309. http://dx.doi.org/10.1023/ B:JMSC.0000039234.58490.78.

9. Viana SG. Obtenção da liga FeSi através do processo mechanical. In: Anais do II Congresso de Pesquisa e Inovação da Rede Norte Nordeste de Educação Tecnológica; 2007; João Pessoa. João Pessoa: IFBA; 2007. 6 p. Available from: <http://www.redenet. edu.br/publicacoes/arquivos/20080108_161921_INDU-067. pdf $>$. Access in: 13/03/2015.

10. American Society for Testing and Materials - ASTM. ASTM A773/A773M-01: Standard test method for dc magnetic properties of materials using ring and permeameter procedures with $d c$ electronic hysteresigraphs. West Conshohocken; 2009.

11. Hewitt SA, Laouli T and Kibble KK. Effect of milling temperature on the synthesis and consolidation of nanocomposite WC-10Co powders. Journal of Refractory Metals and Hard Materials. 2009; 27(1):66-73. http://dx.doi.org/10.1016/j.ijrmhm.2008.03.007.

12. Portal da Pesquisa-CAPES. Crystmet (BDEC): toth information systems. Brasília: CAPES; 2015. Avalible from: <http://www. portaldapesquisa.com.br>. Access in: 13/03/2015.

13. Lisher EJ, Wilkinson C, Ericsson T, Haggstrom L, Lundgren L and Wappling R. Studies of the magnetic structure of Fe3P. Journal of Physics. C. Solid State Physics. 1974; 7(7):13441352. http://dx.doi.org/10.1088/0022-3719/7/7/026.
14. Kumar A, Jayasankar W, Debata M and Mandal A. Mechanical alloying and properties of immiscible $\mathrm{Cu}-20 \mathrm{wt} \%$ Mo alloy. Journal of Alloys and Compouds. 2015: 1040-1047.

15. Gu YW, Goi LS, Jarfors AEW, Butler DL and Lim CS. Structural evolution in Ti-Si alloy synthesized by mechanical alloying. Physica B, Condensed Matter. 2004; 352(1-4):299-304. http:// dx.doi.org/10.1016/j.physb.2004.08.001.

16. Gabrielov I. P/M high strength magnetic alloys. Advances in Powder Metallurgy and Particulate Materials. 2001; 7:10-21.

17. Verma N. Effect of phosphorous addiction as sintering in sinterhardened alloy steel. [Term paper]. Kanpur: Indian Institute of Technology; 2007.

18. Taghvaei AH, Ebrahimi A and Ghaffari M. Investigating the magnetic properties of soft magnetic composites based on mechanically alloyed nanocrystalline $\mathrm{Fe}-5 \mathrm{wt} \% \mathrm{Ni}$ powders. Journal of Magnetism and Magnetic Materials. 2011;323(1):150156.

19. Koohkan R, Sharafi S, Shokrollahi H and Janghorban K. Preparation of nanocrystalline $\mathrm{Fe}-\mathrm{Ni}$ powders by mechanical alloying used in soft magnetic composites. Journal of Magnetism and Magnetic Materials. 2008; 320(6):1089-1094. http://dx.doi. org/10.1016/j.jmmm.2007.10.033.

20. Shokrollahi H and Janghorban K. The effect of compaction parameters and particle size on magnetic properties of iron-based alloys used in soft magnetic composites. Materials Science and Engineering. 2006; 134(1):41-43. http://dx.doi.org/10.1016/j. mseb.2006.07.015. 